\title{
A match made in heaven or down under? The effectiveness of matching visual and verbal horizons in advertising
}

\begin{abstract}
According to construal level theory, consumers' processing styles become more abstract as psychological distance increases, but they grow more concrete when psychological distance decreases. This study provides evidence that panoramic pictures in which the horizon appears in the lower versus upper part of the frame trigger a different level of construal. As such, this paper raises a novel source of construal. In addition, this papers shows that when both visual (e.g., horizon height) and verbal (e.g., temporal benefit) advertising elements induce the same level of construal, advertising effectiveness increases. This work differs from previous research in that it focuses on the construal fit evoked by two ad features rather than a fit in construal between an external stimulus and the internal mindset of the consumer.
\end{abstract}

Keywords: advertising effectiveness, construal fit, processing fluency, panoramic pictures, horizon height 
In this paper we posit a visual feature - the horizon height in panoramic pictures - as a new source of construal. Panoramic pictures are commonly adopted in contemporary advertising, especially by environmentally friendly organizations (e.g., WWF, Rainforest Alliance, The Nature Conservancy), brands with products that originate from nature such as bottled water (e.g., Evian, Fiji, Nestlé), or brands whose products can be used in nature such as sporting goods or cars. For example, Nike shows a jogger running through an endless landscape; Volkswagen often depicts vehicles cruising through rough or idyllic landscapes. However, products and services unrelated to natural environments and landscapes also have been promoted using panoramic scenes, such as luxury watches (e.g., Wryst, Breitlin, Guess), soft drinks (e.g., Coca-Cola), and energy drinks (e.g., MonsterEnergy). We propose that the stylistic properties of such panoramic scenes should receive careful consideration as different horizon heights in panoramic pictures evoke different levels of construal.

According to construal level theory (CLT) (Wakslak, Trope, Liberman, \& Alony, 2006), people represent psychologically near events (i.e., geographically, temporally, socially, or hypothetically near) at lower-level construals which can be defined as "concrete, relatively unstructured, and contextualized representations," whereas psychologically distant events are represented by higher-level construals which are "abstract, schematic, and decontextualized representations"(Liberman \& Trope, 2008, pp. 1201-1202). We argue that panoramic pictures might induce either a concrete or an abstract processing style depending on the height of the horizon: A panoramic picture with a low horizon, positioned in the lower one-third of the picture frame, induces a feeling of looking up, which serves as a distance cue and prompts abstract processing (Van Kerckhove, Geuens \& Vermeir, 2015). Low horizons then should lead to more abstract processing. In contrast, panoramic pictures with a high horizon positioned in the upper one-third of the frame should induce more concrete processing, by evoking a feeling of looking down. As such, this research contributes to the literature on 
visual aesthetics and construal level theory by identifying horizon height in panoramic pictures as an antecedent of construal level.

A mere visual antecedent or prime of construal level is quite unique in consumer research and construal level theory. In previous research, primes of construal are mostly verbal, whereas in real life all kinds of situational cues can determine processing strategies. For example, a commonly used research practice is priming a difference in construals by a written text asking participants to imagine certain remote scenes (i.e., abstract) or proximal scenes (i.e., concrete) (Liberman \& Trope, 1998) or asking them to generate category labels for objects (i.e., abstract) or examples of objects (i.e., concrete) (Fujita et al., 2006). Another often used method is asking participants to write down the why's (i.e., abstract) or the how's (i.e., concrete) of an activity (McCrea, Liberman, Trope, \& Sherman, 2008). Only a hand full of studies use non-verbal primes. Slepian, Masicampo and Ambady (2015), for example, provide evidence that watching a picture with a high (i.e., abstract) versus low (i.e., concrete) camera angle can evoke a different construal level. Hansen and Wänke (2008) and Marzocchi, Pizzi, and Scarpi (2016) primed construals by showing participants a picture of a road with an arrow pointing to a section of the road far (i.e., abstract) or close (i.e., concrete) from the observer. Similarly, this paper adds to construal level theory by bringing forward another visual prime of construal level: the horizon height in panoramic pictures.

In addition, our argumentation integrates insights from construal level theory (Dhar \& Kim, 2007; Liberman, Trope, \& Wakslak, 2007; Trope \& Liberman, 2010, 2011) and research on processing fluency (Lee \& Aaker, 2004; Zhao \& Xie, 2011). Next to visual elements, also verbal messages have the potential to evoke specific construal levels (Förster, Friedman \& Liberman, 2004). In this respect, messages that refer to benefits in the near present or distant future can induce more concrete or abstract processing styles, respectively (e.g., Chang, Zhang \& Xie, 2015; Spassova \& Lee, 2013). We reason that the influence of panoramic 
features on advertising effectiveness might be particularly powerful when this visual element matches the verbal advertising elements in terms of the evoked level of construal:

Since a fit in processing styles yields higher processing fluency (Lee \& Aaker, 2004) we propose that the fit between the construal levels prompted by different ad elements (i.e., visual and verbal elements) evokes higher levels of advertising effectiveness via an increase in processing fluency. This proposition differs from previous research, which has exclusively pointed to the importance of the fit between the viewers' mindset and ad elements (e.g., Lee et al., 2010). By focusing on the fit between multiple in-ad elements our research yields recommendations that can be more easily implemented by advertisers as they fully control all advertising features.

\section{Theoretical Framework}

\section{Horizon Position and Construal Level}

The horizon refers to the line where sky and land appear to meet (Bell, 2004); according to Hagerhall, Purcell, and Taylor (2004), it is the dominant edge in a typical landscape image. Arriazia, Canas-Ortega, Canas-Madueno, and Ruiz-Aviles (2004) and Hagerhall et al. (2004) also identify the character of the horizon as a significant influence on perceptions of a landscape scene. Yet, little research addresses the effects of the stylistic properties of horizons in panoramic pictures. The few exceptions focus on whether the perceived attractiveness of a landscape depends on the characteristics of the horizon (e.g., presence of mountains; Arriaza, Canas-Ortega, Canas-Madueno, \& Ruiz-Aviles, 2004) or its positioning according to the rule of thirds or golden ratio (Kent, 1995; McManus \& Weatherby, 1997; Svobodova, Sklenicka, Molnarova, \& Vojar, 2014). According to the rule of thirds, important compositional elements in pictures should be placed at the horizontal lines 
that mark the division of the picture into thirds, as well as between the two vertical lines that represent the middle third, to produce aesthetically pleasing pictures (Livio, 2003; McManus \& Weatherby, 1997; Peterson, 2015). This rule creates a balanced design, which evokes pleasant perceptions; for example, photographers often use the rule of thirds to determine the most appealing position of a horizon (Svobodova et al., 2014). Accordingly, research on horizon heights in panoramic pictures reveals that raising or lowering the horizon in a picture frame produces different focal points in the picture. A horizon positioned in the lower part of the picture (Figure 1a) accentuates the sky, so viewers' attention is drawn to the sky. In contrast, positioning a horizon in the upper part of the picture (Figure 1b) draws viewers' attention to the elements in the landscape rather than to those in the sky (Kent, 1995).

Based on this finding, one could argue that horizon height influences the evoked construal level because people attend to more concrete, nearby versus abstract, distant information in the landscape, and perceived distance is a proxy for construal level. This research, however, anticipates a more complex relationship and deepens the rationale on why exactly a perceptual change (i.e., perceived distance of objects) causes a change in conceptual processing. To this end, we rely on the theory of mental simulation suggesting that conceptual operations are largely influenced by (simulated) bodily states or actions. Specifically, we argue that viewing a panoramic picture with a low or high horizon causes people to imagine looking up or down, which function, respectively as distance versus proximity cues, and as such, induce more abstract or concrete construals.

According to the theory of mental simulation (Bonnet, Decety, Jeannerod, \& Requin, 1997; Decety \& Ingvar, 1990; Decety, Jeannerod, Durozard, \& Baverel, 1993; Elder \& Krishna, 2012; Zatorre \& Halpern, 2005), when people encounter an object, scene, or representation of them, those images simulate initial perceptions of the object or scene, which also include replays of previous perceptions of that object/scene. For example, when 
consumers eat chocolate, their brains encode all sensory perceptions related to that item (e.g., texture, smell, taste). Later, when thinking about consuming chocolate, they mentally simulate these prior perceptions associated with the chocolate (Elder \& Krishna, 2012). Therefore, when people are exposed to a panoramic picture, they likely mentally simulate viewing such a landscape in reality.

According to Van Kerckhove et al. (2015), when people attend to objects in the upper (i.e., above eye level) or lower (i.e., below eye level) part of the visual field, they also engage in bodily movements, such as upward or downward head or eye movements. If people look at the sky, they usually look up; when they consider concrete events in the landscape, they look down. Therefore, when people encounter a panoramic picture with a low horizon, which implies mainly presenting sky and therefore draws their focus to the sky, a mental simulation of looking up at the sky likely takes place. In contrast, when they regard a panoramic picture with a high horizon, the mental simulation of looking at concrete aspects in the landscape gets instigated, creating a feeling of looking down. We accordingly predict:

H1. When exposed to a panoramic picture with a low horizon, people sense a feeling of looking up, whereas a panoramic picture with a high horizon induces a feeling of looking down.

Extant research has shown that looking up (vs. down) is strongly associated with distance (vs. proximity) and more abstract (vs. concrete) construal levels (Van Kerckhove et al., 2015). As mental simulation prompts neural activation similar to sensory perceptions (Bonnet et al., 1997; Decety \& Ingvar, 1990; Decety et al., 1993; Elder \& Krishna, 2012; Zatorre \& Halpern, 2005), the mental simulation of looking up versus down is suggested to have similar consequences than actual looking up or down. 
In summary, (1) people who perceive a low horizon in a panoramic picture imagine themselves looking up, but people perceiving a high horizon in a panoramic picture imagine themselves looking down (H1); (2) imagining looking up versus down serves as a distance versus proximity cue (Van Kerckhove et al., 2015); and (3) perceived distance versus proximity evokes abstract versus concrete construals (Wakslak et al., 2006). Combining these three predictions, we expect that differences in horizon height lead to different construal levels. Therefore, we hypothesize:

H2: A panoramic picture presenting a low (high) horizon induces more abstract (concrete) processing compared with a panoramic picture showing a high (low) horizon.

H3: The effect of horizon height on construal level is mediated by the mental simulation of looking up versus down and the accompanying perceived distance.

As such, we believe that the effect of horizon height on construal levels is initiated through a difference in the mental simulation of looking up versus down (see figure $2 a$ ), and not merely by attending to nearby or distant objects in the scene.

Besides inducing a simulation of looking up versus down, a low versus high horizon height could also affect the experience of verticality (i.e., being situated at an upward or downward physical location). According to Aggarwal and Zhao (2015) and Slepian et al.(2015), the experience of verticality also influences construal level. Being physically higher up gives people a broader view of a situation, which evokes a higher level of construal than being physically on a ground floor or low point. As such, experienced verticality poses a viable alternative mechanism via which horizon height could affect construal level. Although we agree that it is intuitively compelling to assimilate the effects of low horizons/looking up (high horizons/looking down) with low verticality (high verticality) effects as low verticality 
(high verticality) and looking up (down) are frequently associated, this proposition is not as straightforward as it appears. Specifically, it is inherent to the definition of experienced verticality that it is about the relative position of oneself to the external environment. Horizon height, however, is not informative on vertical positioning as verticality can be low or high, both when the horizon is low or high. Consequently, we expect horizon height to influence construal level through a simulation of looking up versus down, whereas the experience of verticality likely constitutes an independent factor also capable of influencing construal level (See Appendix I for pictures illustrating the independence of horizon height and verticality).

Correspondingly, this research also differs from the effect of camera angle on construal level (Slepian et al., 2015) as verticality is an inherent aspect of camera angle. In case of a high versus low camera angle the viewer looks, respectively, down versus up at a certain object, which is positioned relatively low or high compared to the viewer. In line with our reasoning concerning verticality: when having a low or a high horizon, camera angle can still be high or low (See Appendix I).

\section{Construal Fit between Horizon Height and Advertising Slogans}

Verbal messages can evoke abstract or concrete construals by referring to time. For example, temporal references such as "imagine $\mathrm{X}$ will happen next week" or "imagine $\mathrm{X}$ will happen next year" can manipulate people's construal levels (e.g., Chang et al., 2015; Spassova \& Lee, 2013; Trope \& Liberman, 2000, 2003). Slogans referring to short-term benefits ("Recycle for a Better Calgary Today") versus long-term benefits ("Recycle for a Better Calgary Tomorrow") have been shown to induce different levels of construal (White, MacDonnell, \& Dahl, 2011).

Panoramic pictures also appear in combination with such temporal references (Chang et al., 2015). For example, the water brand Icelandspring uses the slogan "Live Longer," Nestlé 
calls for consumers to "Build a sustainable future," and the WWF uses the slogan "Before it's too late." Temporal benefit references - that is, verbal messages that refer to distant versus proximate moments in time - thus seem highly appropriate to use as verbal elements for this study.

Plenty of research underscores the importance of perceived fit as a means to generate positive outcomes. The match-up hypothesis, for example, highlights the importance of fit between endorsers and the products they promote (Biswas, Biswas, \& Das, 2006; Kahle \& Homer, 1985; Kamins, 1990; Till \& Busler, 2000). Higgins (2000, 2005) and Higgins, Idson, Freitas, Spiegel, and Molden (2003) stress the importance of 'value from fit' and demonstrate that an external stimulus is more impactful when it aligns with the mindset (i.e., regulatory focus) of a decision maker. Malaviya, Kiesilius and Sternthal (1996) mention the importance of fit between the communication objective and the type of elaboration evoked by the picture.

In addition, Thompson and Hamilton (2006) show that in case the consumers' inherent processing mode is compatible with the processing mode induced by the ad, effectiveness increases through enhanced processing ability. More directly related to our purposes, research on the congruency effect of construal levels reveals that external stimuli, such as ad elements, become more persuasive when their level of representation fits the consumer's construal (Dhar \& Kim, 2007; Zhao, Hoeffler \& Zauberman, 2007; Zhao \& Xie, 2011). For example, Zhao and Xie (2011) show that others' recommendations (i.e., high social distance) lead to a greater preference shift when people make decisions for distant-future consumption (i.e., high temporal distance mindset) compared to near-future consumption. Similarly, Zhao and Xie (2011) provide evidence that ad elements compatible with the processing mode of the consumer raise ad effectiveness through an increase in processing fluency. 
Because advertising effectiveness increases when processing fluency increases (Lee \& Aaker, 2004), it seems logical that when ad elements fit in terms of construal and evoke processing fluency, ad effectiveness will increase as well. As such, in this specific case, panoramic ads should feature ad elements (e.g., verbal messages that accompany the panoramic picture) that fit the construal level induced by the horizon height in the panoramic picture. In other words, the construal levels evoked by the visual and verbal ad elements should match (see figure $2 b$ ). So we hypothesize:

H4: Advertisements combining visual and verbal advertising elements that evoke the same (versus different) levels of construal increase consumers' processing fluency of the ads.

H5: An increase in processing fluency, caused by a fit in construal evoked by visual and verbal advertising elements, optimizes the attitude toward the ad and the intention to engage in product-related actions.

This conceptual model is different from previous research. Previous studies highlight the fit between a viewer's (natural or primed) mindset and the construal level evoked by a particular ad element (e.g., Lee et al., 2010, Zhao \& Xie, 2011). To the best of our knowledge, no prior research has investigated differences in ad effectiveness resulting from the fit in the construal level evoked by different ad elements.

With a series of four studies and two accompanying pre-tests, we test these predictions. In a first study we find that a low versus high horizon in a panoramic advertisement evokes different mental simulations, associated with looking up versus down. In line with prior research that indicates that looking up versus down cues distance versus proximity, respectively (Van Kerckhove et al., 2015), the second study shows that a low versus high horizon in a panoramic picture induces distinct processing styles and that this 
effect is independent of perceived verticality (Slepian et al., 2015). A third study provides evidence that the mental simulation of looking up versus down underlies the effect of horizon height on construal level. Then, two pretests confirm that both verbal ad messages referring to distant versus proximate benefits and a shift in horizon height evoke a difference in construal level. Lastly, we illustrate in a fourth study how fit versus misfit in the processing style evoked by an advertisement's visual (i.e., horizon height of the panoramic picture) and verbal (i.e., temporal benefits) elements induces varying levels of processing fluency that in turn determine ad effectiveness.

\section{Studies and Results}

\section{Study 1}

The first study investigates whether people indeed imagine looking up versus down when perceiving a panoramic picture with a low versus high horizon (H1). In addition, we measure verticality in order to show that different horizons affect respondents' sense of looking up or down, but not their sense of verticality.

Participants and design. We recruited 100 U.S. respondents from Amazon's Mechanical Turk (MTurk) platform. None of the respondents had to be discarded (47\% men, $M_{\mathrm{age}}=39$ years, $\left.\mathrm{SD}=11.84\right)$. All participants received 40 cents for completing the survey, which took about 5 minutes. In this study, the participants were randomly assigned to one of two conditions (low vs. high horizon) and none of them was familiar with the picture or study measurements.

Procedure and stimuli. After being welcomed to the online session, the participants read that the researchers were interested in their perceptions of a panoramic picture. Next, participants in the low horizon condition were exposed to the panoramic picture in Figure 1a, while those in the high horizon condition were exposed to the panoramic picture in Figure $1 \mathrm{~b}$. 
The picture shown in the low and high horizon condition was the same differing only in horizon height. Viewing the pictures did not require any actual bodily movement as the picture size allowed people to see the complete picture in one glance. After exposure to the pictures, respondents filled out the questionnaire.

Measurements and reliability. Five items measured whether people imagined looking up versus down while viewing the picture (7-point scales, $\alpha=.74$ ). First, participants had to indicate to what extent they "Imagined looking down at the lake (1) versus looking up at the sky (7)." Second, they noted the extent to which they disagreed (1 = "not at all") or agreed $(7=$ "definitely yes") with four statements: "When watching the panoramic picture, I imagined looking at the sky," "When watching the panoramic picture, I imagined looking up," "When watching the panoramic picture, I imagined looking at the lake," and "When watching the panoramic picture, I imagined looking down." The latter two items were reverse coded.

To exclude any confounding effects of (the mental simulation of) verticality, we used two 7-point scales to measure the extent to which people imagined themselves standing somewhere high up or at ground level $(\alpha=.61)$ : (1) "To be able to see this type of view, it is necessary to be somewhere high up (e.g., on top of a mountain, in a helicopter, in an air balloon)," and (2) "To be able to see this type of view, it is necessary to be somewhere at ground level (e.g., at the foot of a mountain, nearby the lake)." The latter item was reverse coded.

Results and discussion. Two one-sample t-tests reveal that a panoramic picture with a low horizon makes people imagine themselves looking up $\left(\mathrm{X}_{\text {neutral }}=4, M_{\text {low }}=4.65, \mathrm{SD}=1.6\right.$, $t(50)=4.06, p<.001)$, whereas a panoramic picture with a high horizon induces a feeling of looking down $\left(\mathrm{X}_{\text {neutral }}=4, M_{h i g h}=3.50, \mathrm{SD}=1.7, t(48)=-2.99, p=.004\right)$. Moreover, a 
multivariate analysis of variance (MANOVA) reveals that the difference in imagining looking up versus down is significant between conditions $(F(1,98)=24.66, p<.001)$, but the difference in perceived verticality is not $\left(M_{\text {low }}=2.57, \mathrm{SD}=1.3, M_{\text {high }}=2.54, \mathrm{SD}=1.39\right.$, $F(1,98)=.01, n s)$. These results provide support for $\mathrm{H} 1$.

\section{Study 2}

Study 2 investigates the first two hypotheses, namely, that looking at a picture with a different level of horizon induces a mental simulation of looking up versus down (H1) and a different level of construal (H2). In addition, we show that this effect differs from the effect of verticality on construal level. We manipulated both verticality and horizon height in order to show that both manipulations lead toward independent main effects.

Participants and design. For this study, we recruited 231 U.S. respondents from Amazon's Mechanical Turk (MTurk) platform. We only used the responses of 213 respondents $\left(50 \%\right.$ men, $M_{\mathrm{age}}=38$ years, $\left.\mathrm{SD}=10.05\right)$ in our analyses. We excluded those participants $(\mathrm{n}=15)$ who deviated more than three standard deviations from the mean scores on the evident items of the Rosch test (1975), which was included as a measure of construal level. Similar to Slepian et al.'s (2015) method, we asked participants to indicate the extent to which three typical exemplars (e.g., chair, car), three neither typical nor atypical exemplars (e.g., lamp, boat), and three atypical exemplars (e.g., clock, tank) were representative members of a category (i.e., furniture, vehicles) (10-point Likert scale, $1=$ "The item definitely does not belong to the category" to $10=$ "The item definitely belongs to the category”). Ratings above 5 signal inclusion into the category. The order of both the categories and the examples within the categories were random. A more inclusive categorization signifies a more abstract style of processing (Rosch, 1975), so we expect participants exposed to a low horizon to rate all exemplars as better category members than 
would participants exposed to pictures with a high horizon. In addition, those participants who experienced problems with the survey are left out $(n=3)$. All participants received 40 cents for completing the survey, which took about 6 minutes. In this study, the participants were randomly assigned to one of four conditions (low vs. high horizon) X (low vs. high verticality).

Procedure and stimuli. After being welcomed to the online session, the participants read that the researchers were interested in mental simulations. Next, participants in the low versus high verticality conditions read the following instructions: "You are going to a gallery exhibiting photographs. The building the gallery is vested in has five floors. The gallery is vested underground at the lowest floor [above ground at the top floor] and is a square room without windows." This manipulation of verticality is based on the one used by (Aggarwal \& Zhao, 2015). Next, participants were shown a picture that ostensibly was exhibited in the gallery. In the low horizon condition participants saw the panoramic picture in Figure 1a, while those in the high horizon condition saw the panoramic picture in Figure 1b. After exposure to the pictures, respondents filled out the questionnaire.

Measurements and reliability. To measure construal level we used the Rosch test (1975), which we explained above.

As a manipulation check we measured the mental simulation of looking up versus down, perceived distance, and verticality. The mental simulation of looking up versus down was measured via two items (7-point semantic differential scale, $\alpha=.65$ ): (1) "To what extent did you imagine looking down versus looking up," and (2) “To what extent did you imagine looking at the surface in the front of the pictures versus looking at the sky." Perceived distance was measured via 4 items (7-point, semantic differential scale, $\alpha=.74$ ): (1) "The picture gives me the feeling of having a view from nearby versus of being able to look 
faraway", (2) "The landscape in the picture is nearby versus far-flung", (3) "When looking at the picture I experience nearness versus distance" and (4) "I experience a lack of depth in the picture versus a lot of depth in the picture." Verticality was measured via three items (7-point semantic differential scale, $\alpha=.95$ ): (1) "To what extent did you imagine being underground versus above ground," (2) "To what extent did you imagine being somewhere low versus somewhere high," and (3) "To what extent did you imagine being below the surface versus higher up."

Mood, arousal, and power were measured as potential covariates as they can affect construal level (Slepian et al., 2015). For measuring mood, arousal and power, similar verbal items (without the visual illustration) were used as in the fourth study of Slepian et al. (2015). Three items measured mood, arousal, and power via asking "How do you feel right now?" (9point, bipolar scale: (1) from -4 = "Very unpleasant" to 4 = "Very pleasant", (2) from $-4=$ "calm" to 4 = "excited", (3) from -4 = "powerless" to 4 = "powerful."

Results and discussion. Using a two-way multivariate analysis of variance (MANOVA) our manipulation checks show there is no significant main effect of horizon height on verticality $\left(M_{l o w}=4.27, \mathrm{SD}=2.31, M_{\text {high }}=4.58, \mathrm{SD}=2.25, F(1,209)=2, n s\right)$, whereas the effect on mental simulation of looking up versus down is significant $(F(1,209)=$ $13.96, p<.001)$. A low horizon induces a stronger mental simulation of looking up $\left(M_{l o w}=\right.$ $5.17, \mathrm{SD}=2.04)$ compared to a high horizon $\left.\left(M_{\text {high }}=4.48, \mathrm{SD}=2.04\right)\right)$. In addition, there is no effect of the verticality manipulation on the mental simulation of looking up versus down $\left(M_{\text {low verticality }}=4.70, \mathrm{SD}=.14, M_{\text {high verticality }}=4.92, \mathrm{SD}=.14, F(1,209)=1.41, n s\right)$. The effect of the verticality manipulation on perceived verticality is significant $(F(1,209)=155.05, p<$ $.001)$, with the low verticality condition $\left(M_{\text {low verticality }}=3.01, \mathrm{SD}=2.34\right)$ inducing a lower perceived verticality compared to the high verticality condition $\left(M_{\text {high vertciality }}=5.83, \mathrm{SD}=\right.$ 2.34). 
A two-way analysis of variance (ANCOVA) supports our second hypothesis that viewing panoramic pictures with a different horizon height affects construal level $(F(1,206)=$ $6.85, p=.010)$. Panoramic ads with a low horizon induce more inclusive categorization $(M=$ $7.10, \mathrm{SD}=1.50)$ and, therefore, more abstract construals than do panoramic ads with a high horizon $(M=6.72, \mathrm{SD}=1.46)$. In addition, these results corroborate the findings of Slepian et al. (2015) as the verticality manipulation also led to a marginally significant difference in the inclusiveness of categorizations $(F(1,206)=2.95, p=.09)$. Low verticality $(M=6.8, \mathrm{SD}=$ 1.46) induces less inclusive categorization, and thus more concrete construals, compared to high verticality $(M=7.03, \mathrm{SD}=1.46)$. There is no significant interaction effect between horizon height and verticality on construal level $(F(1,206)=.04, n s)$. As such, we can conclude that both horizon height and verticality—independently—affect construal level. Mood and arousal are not significant as covariates. Power is a significant covariate $(F(1,206)$ $=8.52, p=.004)$. The latter can be explained by the fact that verticality is often used as a metaphor for power (Lackoff \& Johnson, 1980 in Slepian et al., 2015).

To test the underlying process (H3), we conducted a mediation analysis featuring horizon height $(0=$ high horizon, $1=$ low horizon $)$ as the independent variable, construal level as the dependent variable, and perceived mental simulation of looking up versus down and perceived distance as serial mediators. We controlled for the effect of the manipulation of verticality as we included this variable in the model as a covariate. Mood, arousal, and power were also included as covariates. We predicted that a downward shift in horizon would lead to a stronger mental simulation of looking up, which increases the distance perception, and this, in turn, would evoke a more abstract construals.

An one-way analysis of covariance shows that the total direct effect of horizon height on construal level is significant $(F(1,207)=6.92, p=.009)$. Power $(F(1,207)=8.58, p=.004)$ and verticality $(F(1,207)=2.95, p=.088)$ emerge as significant covariates, but mood $(F(1$, 
$207)=.07, n s)$ and arousal do not $(F(1,207)=.86, n s)$. According to the serial mediation analysis, the mental simulation of looking up versus down and perceived distance mediate the effect of horizon height on construal level (Preacher \& Hayes, 2004). The analysis, with 10,000 bootstraps and $95 \%$ bias-corrected confidence intervals $(\mathrm{CI})$, reveals a significant serial mediation effect $(a b=.01, \mathrm{SE}=.01,95 \% \mathrm{LLCI}=.001,95 \% \mathrm{ULCI}=.052)($ Hayes, 2013).

\section{Study 3}

In this third study, we apply a "moderation-of-process approach" (Spencer, Zanna \& Fong, 2005) to provide further evidence for our third hypothesis that the effect of horizon height on construal level is mediated by the mental simulation of looking up versus down. The idea is to manipulate the proposed mediating variable (looking up vs. down) and to show that this manipulation interferes with the effect of horizon height on construal level. In case people already have an upwards (or downwards) head orientation or eye orientation, any kind of mental stimulation of head movement by horizon height is likely to be overridden (the actual movement likely is at least equally powerful, or even more powerful, than a mental simulation thereof). If a simulation of looking down versus up is a mediating variable, we can expect the effect of horizon height on construal level to be attenuated when head or eye orientations are fixated upward (or downward). In contrast, in case people look straight ahead, we expect that horizon height does affect construal level because the mental simulation of looking up versus down induced by the horizon height likely is consequential.

Participants and design. We invited 226 students from a large Western European university to a lab to participate in a 50-minute experimental session, in return for partial course credit. We kept 216 participants $\left(44 \%\right.$ men, $\left.M_{\mathrm{age}}=21, \mathrm{SD}=1.22\right)$. Exclusion was due to participants experiencing problems during the study $(n=9)$ and to missing data $(n=1)$. The 
length of this study was about 9 minutes, and all participants were randomly assigned to one of four conditions (i.e., horizon height: low vs. high) $\mathrm{X}$ head orientation (straight ahead vs. up).

Procedure and stimuli. In the first part of Study 3, participants learned that the experimenters were interested in their opinions about several unrelated topics (perceived beauty of panoramic pictures, classification of products into product categories). Each participant saw one picture (see figure $3 \mathrm{a}$ and $3 \mathrm{~b}$ ). To make the cover story believable, respondents rated the perceived attractiveness of the pictures. In the second part of the study, we measured construal level. During both parts of the study, participants were either looking straight ahead or they were looking up. This was manipulated by adapting the position of the screen. In case participants needed to look straight ahead, the position of the center of the screen was at the average eye level height (46.85 inch) (this average eye level height was inferred from the average height of Western European students in relation to the advised height for screens by the Human Solution, 2018), whereas participants in the other condition were obliged to look up to attend to the center of the screen that was placed higher $(58.66$ inch). In both conditions the height of the seat (18.5 inch), keyboard and mousepad on the desk (25.93 inch) were exactly the same.

Measurement and reliability. To measure construal level, we again used the Rosch test (1975). This time we included only the category 'furniture' to limit the duration of the study (in which the participants that were looking up likely were in a less comfortable position).

We added the same measurements as in the second study for mood, arousal, and power as potential covariates (Slepian et al., 2015). In addition, as the looking up condition could have been experienced as somewhat uncomfortable, we measured comfort via 1-item, (7- 
point, bipolar scale) asking to what extent participants agreed with the following statement: \$from $1=$ "During the experiment I was not in a comfortable position" to $7=$ "During the experiment I was in a comfortable position.” An analysis of variance shows no main effect of horizon height on comfort $\left(M_{\text {low }}=4.75, \mathrm{SD}=2.12, M_{\text {high }}=4.89, \mathrm{SD}=2.18, F(1,212)=.001\right.$, $n s)$, but there is a main effect of physical head movement on comfort $(F(1,212)=70.26, p<$ .001). Participants in the looking up condition experience less comfort $(M=3.93, \mathrm{SD}=2.28)$ compared to participants who looked straight ahead $(M=5.71, \mathrm{SD}=2.13)$. The interaction effect of horizon height and the manipulation of looking up versus straight ahead on comfort is not significant $(F(1,212)=.86, n s)$.

Results and discussion. To verify whether viewing panoramic pictures with a different horizon height affects construal levels via the mental simulation of looking up versus down, we ran a two-way ANCOVA. There is a marginally significant main effect of horizon height on construal $(F(1,209)=3.10, p=.080)$ and there is a main effect of physical head movement on construal $(F(1,209)=8.99, p=.003)$. The interaction effect of horizon height and the mental simulation of head/eye movement on CL does not reach conventional levels of significance $(F(1,209)=2.28, p=.132)$. Nevertheless, the results of the simple effects are in line with our expectations. When people look up, there is no significant effect of horizon height on construal $\left(M_{\text {low }}=6.06, \mathrm{SD}=1.15, M_{\text {high }}=6.07, \mathrm{SD}=1.05, F(1,209)=.03, n s\right)$, whereas when people look straight ahead there is a significant effect of horizon height on construal $(F(1,209)=5.60, p=.019)$. In case people look straight ahead, perceiving a picture with a low horizon $(M=6.70, \mathrm{SD}=1.13)$ led to more abstract construals than perceiving a picture with a high horizon $(M=6.27, \mathrm{SD}=1.11)$. The effects of $\operatorname{mood}(F(1,209)=.80, n s)$, arousal $(F(1,209)=.03, n s)$, and power $(F(1,209)=2.13, n s)$ as covariates are not significant. Although, the interaction effect does not reach the conventional level of significance, we believe the simple effects provide evidence for our hypothesis. 


\section{Study 4}

The fourth study investigates whether an advertisement combining visual and verbal ad elements that evoke the same level of construal, rather than one combining visual and verbal ad elements that prompt different levels of construal, enhances consumers' processing fluency of the ad (H4). Furthermore, we determine whether this fit in the verbal advertising message and the visual message optimizes advertising effectiveness via an increase in processing fluency (H5). We started this study with two pre-tests, to confirm that verbal temporal references (i.e., long term benefits vs. short term benefits) and horizon height of the stimulus picture trigger different construal levels.

Pre-test 1: Verbal temporal benefit references and construal levels. With a first pre-test, we investigated whether verbal temporal benefit references instigate differences in processing styles and if both temporal references are equally persuasive. This study invited 85 U.S. residents from MTurk, who received compensation of 40 cents for completing the 5minute study. Of all participants, we kept 82 in the dataset $\left(55 \%\right.$ men, $M_{\text {age }}=40$ years, $\mathrm{SD}=$ 12.42). One participant was excluded as he really disliked the target product, bottled water, in general. Two other participants were excluded as they experienced problems during the study. All participants were randomly assigned to either the long-term or the short-term condition.

The cover story informed the participants that the experimenters were interested in obtaining feedback about an advertising slogan promoting a new brand of water, Wela. We chose bottled water as the focal product, because drinking water offers known benefits in both the long and short term. Using a fictitious brand Wela enabled us to avoid any potential bias due to previous brand perceptions or brand familiarity. Then the long term verbal ad message read, "Wanna live long? Drinking water keeps your hearth healthy. Live the future ... drink Wela Water!" The short term condition instead read, "Wanna cool down? Drinking water 
immediately hydrates you. Live now ... drink Wela Water!” After reading the slogans, in line with the cover story, participants filled out a short questionnaire that asked about their thoughts on the message. Then, in the second part of the study, we measured their construal levels. In the last part, we measured message attractiveness, attitude toward the brand, purchase intentions, and processing fluency.

For message attractiveness, we used three items (7-point semantic differential scales, $\alpha$ = .96): (1)“This slogan is a bad one/good one", (2) "I do not like/I like this slogan", (3) "My opinion on this slogan is negative/positive." For attitude toward the brand, we used a similar measurement approach $(\alpha=.96)$ : (1) "I do not like/I like this water brand", (2) "This is not/This is an attractive brand" and (3) "I feel negative/positive about this water brand." The three items to measure purchase intentions used a 7-point Likert scale $(1=$ "strongly disagree" to 7 = "strongly agree", $\alpha=.93$ ): (1) "It seems a good idea to buy this water brand," (2) "If I would buy water, I would consider buying this brand of water," and (3) "From this moment on I will pay more attention to this water brand while shopping." These assessments enable us to determine if both temporal benefits, in the absence of other ad elements, are equally persuasive. The measure of construal level was the same as in Study 3, relying on Rosch (1975) tests. Finally, we measured ease of processing the slogan as a potential covariate via one item (7 point, semantic differential scale) asking how they felt about the slogan: "the slogan was difficult to understand versus was easy to understand."

The multivariate analysis of covariance (MANCOVA) reveals a significant effect of slogan type (i.e., short term vs. long term benefit) on construal $(F(1,79)=3.99, p=.049)$ : Advertising messages referring to future benefits induce more inclusive categorization $(M=$ $5.95, \mathrm{SD}=1.39)$ than advertising messages referring to short-term benefits $(M=5.52, \mathrm{SD}=$ 1.36). A more or less inclusive categorization is a manifestation of having an abstract versus concrete construal level. These results confirm previous studies that different verbal temporal 
benefit references evoke different construal levels. The persuasiveness of the short- and longterm benefit messages does not differ $\left(M_{\text {short }}=4.44, \mathrm{SD}=1.74, M_{\text {long }}=4.54, \mathrm{SD}=1.81, F(1\right.$, $79)=.01, n s)$, nor do their effects on attractiveness of the brand $\left(M_{\text {short }}=4.81, \mathrm{SD}=1.33\right.$, $\left.M_{\text {long }}=4.66, \mathrm{SD}=1.42, F(1,79)=.59, n s\right)$ or purchase intentions $\left(M_{\text {short }}=4.56, \mathrm{SD}=1.34\right.$, $\left.M_{\text {long }}=4.44, \mathrm{SD}=1.58, F(1,79)=.16, n s\right)$. The effect of ease of processing on construal level as a covariate is not significant $(F(1,79)=1.11, n s)$.

Pre-test 2: Horizon height and construal levels. With a second pre-test, we investigated whether the shift in horizon height in this particular panoramic picture instigates a difference in processing styles. This study recruited 81 participants from an Online Panel of a large Western European university, who participated in return for entering in a lottery in which they could win a coupon worth 20 euros (17.60 US dollars) for "bol.com”. We kept 73 participants in the database $\left(23 \%\right.$ men, $M_{\text {age }}=21$ years, SD $\left.=5.11\right)$. Eight participants were excluded from the analysis: one participant due to missing data, one participant failed the attention check and six other participants experienced problems during the study. All participants were randomly assigned to either the high horizon or the low horizon condition.

In the first part of this pre-test, participants learned that the experimenters were interested in their opinions about several unrelated topics (perceived beauty of panoramic pictures, classification of products into product categories). Each participant saw one picture. The same picture was shown in the low and high horizon condition, differing only in horizon height (see figure $4 \mathrm{a}$ and $4 \mathrm{~b}$ ).

In the second part of the study, we measured our dependent variable: construal level. We used the Rosch test (1975) as in the second and the third study. This time we included only the category 'vehicles'. In addition, we measured attractiveness $(\alpha=.76)$, mood, arousal, and power as in previous studies (Slepian et al., 2015). 
The multivariate analysis of covariance (MANCOVA) reveals a marginal significant effect of horizon height on construal $(F(1,68)=3.79, p=.056)$ : A picture with a low horizon induces more inclusive categorization $(M=8.40, \mathrm{SD}=1.66)$ than a picture having a high horizon $(M=7.89, \mathrm{SD}=1.46)$. These results confirm our previous studies that a shift in horizon height in picture frames evokes different construal levels. The attractiveness of the picture does not differ $\left(M_{\text {low }}=5.60, \mathrm{SD}=1.13, M_{h i g h}=5.34, \mathrm{SD}=1.28, F(1,68)=.507, n s\right)$. The effects of $\operatorname{mood}(F(1,68)=.26, n s)$, arousal $(F(1,68)=.74, n s)$, and power $(F(1,68)=$ $.31, n s)$ on construal level as covariates are not significant.

\section{Main study: Construal fit between visual and verbal elements and ad}

effectiveness. Our goal for this fourth study is to investigate whether advertisements combining visual and verbal elements that evoke the same level of construal are perceived as easier to process than advertisements that contain visual and verbal ad elements that induce different levels of construal (H4). Furthermore, we consider whether the increase in processing fluency caused by construal fit between visual and verbal ad elements also increases advertising effectiveness (H5).

Participants and design. This study recruited 234 students from a large Western European university, who participated in a 50 minute session in return for a partial course credit. In total, 229 participants were kept in the sample ( $46 \%$ men, $M_{\text {age }}=21$ years). Participants who were extremely skeptical about the truth of the claim were left out $(n=5)$. More specific, at the end of the survey, we measured to what extent people believed the ad claim was true. Therefore, we used a one item, 9-point Likert scale asking: To what extent do you believe the ad claim is (not) true $(1=$ 'this ad claim is not true' to $9=$ 'this ad claim is true'). We excluded the participants indicating "1". All participants were randomly assigned to one of four conditions, in a 2 (horizon height: low vs. high) $\times 2$ (verbal message: long-term vs. short-term) experimental design. 
Procedure and stimuli. The respondents read that the experimenters were interested in obtaining feedback on an advertisement promoting a new brand of water, Wela. Of the four conditions, two feature construal level fit in their ad elements (i.e., horizon height and advertising message both induce abstract or concrete construals), and two conditions feature a construal misfit (i.e., horizon height and advertising message induce different levels of construal) (see figures 5a, 5b, 5c and 5d). To determine the effect of construal fit, we compare the two fit conditions against the two misfit conditions. By including both fit conditions, we ensure that the effect is solely due to perceptions of fit, regardless of whether both advertising elements evoke a concrete or abstract construals. After exposure to the advertisements, the participants completed the questionnaire.

Measurements and reliability. Our measure of ad effectiveness included attitude toward the ad and the intention to subscribe for free samples. For attitude toward the ad, we used three items (7-point semantic differential scales, $\alpha=.94)$ : (1) “This advertisement is a bad versus a good one," (2) "I do not like versus like this advertisement," (3)“My opinion on this advertisement is negative versus positive." The intention to subscribe for free samples was coded " 0 " in case no contact information was provided in order to enter a lottery for winning free samples and " 1 " in case contact information was provided.

We measured processing fluency with a five-items, making use of different measurements previously used in literature (7-point bipolar scales, $\alpha=.91$ ). The items were the following: The ad was (1) "difficult versus easy to process" (Lee \& Aaker, 2004), (2) “difficult versus easy to understand" (Lee \& Aaker, 2004), (3) "no effort versus a lot of effort was required to understand the ad" (Hermann et al., 2013), (4) "the ad was very simple versus very complex" (Miele \& Molden, 2010), and (5) "understanding the ad required effort versus no effort” (Miele \& Molden, 2010). 
Results and discussion. First, an analysis of variance (ANOVA), confirms our fourth hypothesis: Respondents who see an advertisement characterized by construal fit experience higher processing fluency $(M=5.09, \mathrm{SD}=1.68)$ compared with respondents who see an advertisement characterized by construal misfit $(M=4.76, \mathrm{SD}=1.69 ; F(1,227)=4.54, p=$ .034). The results of an analysis of variance (ANOVA), featuring 'horizon height' and 'fit versus misfit' as independent variables and processing fluency as dependent variable, show no main effect of horizon height, $F(1,225)=.06, n s)$, but a main effect of fit versus misfit, $F(1$, $225)=4.48, p=.035)$. The interaction effect of horizon height and 'fit versus misfit' is not significant, $F(1,225)=.004, n s)$.

Second, the results of a regression analysis show that when processing fluency is high the attitude toward the ad $(\beta=.43, t(227)=7.34, p<.001)$ increases. In addition, when processing fluency is high, the intention to subscribe for free samples grows as well. A logistic regression was performed to ascertain the effects of processing fluency on the intention toward obtaining free samples. The model is significant $\left(\chi^{2}(1)=4.60, p<.035\right)$.

Third, to test the underlying process (H5), we conducted two mediation analyses featuring fit $(0=$ misfit, $1=$ fit $)$ as the independent variable; attitude toward the ad and the intention toward receiving free samples as the dependent variables; and processing fluency as a mediator. We predicted that a fit would enhance processing fluency leading to higher add effectiveness.

A multivariate analysis of variance (MANOVA) and a logistic regression show that the total direct effect of fit on attitude towards the ad $\left(M_{f i t}=4.68, \mathrm{SD}=1.69, M_{m i s f i t}=4.63\right.$, $\mathrm{SD}=1.66, F(1,227)=.08, n s)$ and the intention to subscribe for free samples $($ fit $=41.38 \%$, misfit $=34.51 \%, F(1,227)=.86, n s)$ is not significant. According to the mediation analyses, 
processing fluency mediates the effect of construal fit versus misfit on both dependent variables (Preacher \& Hayes, 2004). The first mediation analysis, with 10,000 bootstraps and 95\% bias-corrected confidence intervals $(\mathrm{CI})$, reveals a significant indirect mediation effect only (Zhao, Lynch, \& Chen, 2010) for attitude toward the ad $(a b=.14, \mathrm{SE}=.0795 \%$ LLCI: $=.014,95 \%$ ULCI $=.307)($ Hayes, 2013). In more detailed analyses, we find that the remaining indirect effect of fit on attitude towards the ad is not significant $(t(226)=-1.35, n s)$. A similar pattern holds for the intention to subscribe for free samples $(a b=.08, \mathrm{SE}=.06$, 95\% LLCI: $=.003,95 \%$ ULCI $=.251)$ as the dependent variable (Figure 6).

\section{Discussion}

Viewing a low versus a high horizon in a panoramic picture provokes a difference in the extent to which people mentally simulate looking up versus down. This mental simulation in response to seeing a panoramic picture activates the same brain regions as actual sensory experiences (Bonnet et al., 1997; Decety \& Ingvar, 1990; Decety et al., 1993; Elder \& Krishna, 2012; Zatorre \& Halpern, 2005), such that it simulates looking up or down. In line with Van Kerckhove et al. (2015), who find that looking up versus looking down represent distance versus proximity cues that evoke different processing styles, we also find that presenting a low versus high horizon in a panoramic ad leads to differences in construal levels. A pre-test replicates previous research (Chang et al., 2015) and shows that verbal advertising messages can induce abstract or concrete processing, by referring to diverse temporal distances that induce thinking about the long term versus the short term. When we combine both visual (i.e., horizon height) and verbal (i.e., temporal benefit references) advertising elements in a single ad, we also show that advertising effectiveness depends on the construal fit between these elements. If both horizon height and verbal temporal benefit references induce the same level of construal, processing fluency increases, and that leads to 
increased ad effectiveness. In contrast, combinations of elements arousing different levels of construal lead to diminished processing fluency and, as such, lower advertising effectiveness.

\section{Theoretical Implications}

This investigation contributes to previous research in several ways. In particular, we extend insights into the use of landscapes by taking a unique perspective. Previous research mainly focuses on evolutionarily derived landscape preferences and the positive effects on people's psychophysiological and emotional states (e.g., Cackowski \& Nasar, 2003; Falk \& Balling, 2009; Hartmann \& Apaoloza, 2010; Kaplan, 1987; Ulrich, 1983). Rather than evolutionary effects, psychophysiological elements, or emotional states, we consider the cognitive processing styles induced by the horizon height in a panoramic picture (i.e., abstract vs. concrete processing).

In turn, this study contributes to the research investigating the stylistic properties of advertisements (Meyers-Levy \& Peracchio, 1992). The orientation (e.g., vertical or diagonal) of objects displayed in a scene, cropped images in ads, and camera angles previously have been investigated as stylistic properties (Peracchio \& Meyers-levy, 2005); we add the positioning of the horizon to this list of stylistic elements. Shifting the horizon in a panoramic picture is different from cropping a panoramic picture, because the relative height of the horizon might remain the same after cropping. It also is distinct from taking a different camera angle (see appendix I): Downward-angle pictures are taken from high places (e.g., top of a canyon or staircase; Slepian et al., 2015) and/or represent the view from above (Aggarwal \& Zhao, 2015; Cian, 2015; Van Rompay, de Vries, Bontekoe, \& Tanja-Dijkstra, 2012), whereas upward-angle pictures are taken from low positions (e.g., at the foot of a tree looking up at the leaves; Slepian et al., 2015) and/or represent the view from below (Aggarwal \& Zhao, 2015; Cian, 2015; Van Rompay et al., 2012). In contrast, panoramic pictures that 
present the horizon at different heights might be taken from exactly the same spot, without requiring any vertical change in position. In addition, it is not possible, when shifting the horizon height, to present a landscape purely from below (i.e., mere presentation of the sky) or above (i.e., mere presentation of the ground); the very presence of the horizon inherently implies the visualization of both the sky and the ground. As such, our article makes an argument for adding horizon height to the list of stylistic properties that can determine advertising effectiveness.

For CLT literature, this study provides several insights. First, no prior research has focused on whether or how the visual element "panoramic pictures" affects construal levels; this contribution accordingly proposes and provides evidence for a novel source of construal. Second, we extend current theory on the effect of spatial distance on construal levels. Specifically, we demonstrate that in addition to actual experienced distances, the priming of this experience (Trope \& Liberman, 2010, 2011; Williams \& Bargh, 2008), or an actual experience of looking up versus down (Van Kerckhove et al., 2015), an implicit trigger of mental simulation of looking up versus down is sufficient to affect people's processing style. According to Ostinelli, Luna, and Ringberg (2014), the influence of mental simulation on judgments offers an advantage over actual sensory-motor experiences in that it can be used more readily in communication contexts. Third, we add to the context of experimental research in construal level theory by providing a visual (rather than a verbal) prime of construal level.

Finally, we confirm that construal fit conditions enhance consumers' attitudes and evaluations (Lee \& Aaker, 2004; Lee et al., 2010). Here, we stress that the results of this article are strongly related to but differ from the congruency effect of construal levels (Dhar \& Kim, 2007; Zhao et al., 2007; Zhao \& Xie, 2011). That is, in our studies, we did not construct any match between the advertising content and the type of construal inherent (i.e., primed or 
by nature) to the person. Instead, fit arose between the type of construal evoked by visual and verbal advertising elements. This type of construal fit increases processing fluency, which in its turn enhances advertising effectiveness.

\section{Practical Implications}

Marketers can use the results of this study as input for their advertising strategies. Horizon height in panoramic pictures induces different types of processing, so marketers must consider the effect of their panoramic ads to determine the scope of consumers' perspective in general. Previous research indicates that when consumers adopt an abstract processing style (broad perspective), they attach more weight to the advantages of a remote situation (Eyal, Liberman, Trope, \& Walther, 2004), and they exhibit increased moral behavior (Agerström \& Björklund 2009; Eyal, Liberman, \& Trope 2008; Eyal, Sagristano, Trope, Liberman, \& Chaiken, 2009) and willingness to pay (Ledgerwood, Wakslak, \& Wang, 2010). Consequently, for marketers engaged in fundraising, promoting long-term beneficial products, or seeking to encourage a broad scope among consumers, their advertising stimuli should evoke abstract processing, and we reveal that it may be advisable for them to include a panoramic picture with a low horizon.

Adopting a concrete style of processing is beneficial in other situations though. For example, it helps people make compromises, because a concrete mindset emphasizes difficulties, costs, and situational pressures (Khan, Zhu, \& Kalra, 2011). For products marketed mainly as preventatives for instant difficulties or costs, marketers thus might develop panoramic advertisements with a high horizon to evoke concrete processing.

Finally, this article underscores the need for marketers to design advertising in which the visual and verbal elements fit their evoked construal levels, to increase consumers' favorable attitudes. 


\section{Limitations and Further Research}

The results of this study must be framed according to its limitations. All the studies were conducted with surveys in an experimental or online setting in which the ad exposure and processing were atypical in several ways. For example, the ads appeared on the participants' computer screen in the lab or at home, and the exposure was forced and limited. These factors may have induced a processing mode different from the one that consumers would usually adopt when viewing print ads in their daily lives, as well as increased the level of ad involvement, relative to the general level of involvement with advertising messages in real life. Because the experiments sought to test theory-based predictions, we chose these conditions to maximize internal validity; further research might try to replicate our findings in a semi-field study environment to affirm their generalizability. For example, it is possible that an ad on a bigger versus smaller screen (e.g., an ad in the cinema vs. on your mobile phone) more readily activates a mental simulation of looking up versus down and as such produces stronger effects of horizon height.

Other external validity issues also need to be taken into account. For example, the test ad was developed to match the experimental conditions, rather than using an existing advertisement. Further research could attempt to match professionally designed, existing ads with the respective experimental conditions. Moreover, our experimental design only features one product (i.e., bottled water), which limits the findings to this product class. Continued research could replicate our study using other products to further increase generalizability.

Finally, we only measured self-reported mental simulations of looking up versus down and self-reported processing fluency. Researchers also might measure participants' neural activation while they view the ads to advance these insights. 
Overall though, this research offers new implications for research and practice, by confirming that looking at a panoramic picture in which that horizon appears in the lower versus upper part of the frame evokes different levels of construal. In addition, we show that combining verbal and visual elements that evoke the same level of construal enhances consumers' processing fluency and thus advertising effectiveness.

\section{REFERENCES}

Agerström, J. \& Björklund, F. (2009). Moral concerns are greater for temporally distant events and are moderated by value strength. Social Cognition, 27(2), 261-282.

Aggarwal, P. \& Zhao, M. (2015). Seeing the big picture: The effect of height on the level of construal. Journal of Marketing Research, 52(1), 120-133.

Arriaza, M., Canas-Ortega, J. F., Canas-Madueno, J. A., \& Ruiz-Aviles, P. (2004). Assessing the visual quality of rural landscapes. Landscape and Urban Planning, 69(1), 115125.

Bell, S. (2004). Elements of visual design in the landscape. New York: Taylor \& Francis.

Biswas, D., Biswas, A. \& Das, N. (2006). The differential effects of celebrity and expert endorsements on consumer risk perceptions. Journal of Advertising, 35(2), 17-31.

Bonnet, M. E., Decety, J., Jeannerod, M. \& Requin, J. (1997). Mental simulation of an action modulates the excitability of spinal reflex pathways in man. Cognitive Brain Research, 5(3), 221-228.

Cackowski, J. M. \& Nasar, J. L. (2003).The restorative effects of roadside vegetation: Implications for automobile driver anger and frustration. Environment and Behavior, 35(6), 736-751. 
Chang, H., Zhang, L. \& Xie, G. X. (2015). Message framing in green advertising: The effect of construal level and consumer environmental concern. International Journal of Advertising, 34(1), 158-176.

Cian, L. (2015). The conceptual effects of verticality in design. In R. Batra, C. Seiftert, \& D. Brei (eds.), The Psychology of Design: Creating Consumer Desire (pp. 40-52). New York: Routledge.

Decety, J. \& Ingvar, D. (1990). Brain structures participating in mental simulation of motor behavior: A neuropsychological interpretation. Acta Psychologica, 73(1), 13-34.

Decety, J., Jeannerod, M., Durozard, D., \& Baverel, G. (1993). Central activation of autonomic effectors during mental simulation of motor actions in man. Journal of Physiology, 461(1), 549-563.

Dhar, R. \& Kim, E. Y. (2007). Seeing the forest or the trees: Implications of construal level theory for consumer choice. Journal of Consumer Psychology, 17(2), 96-100.

Elder, R. S. \& Krishna, A. (2012). The visual depiction effect in advertising: Facilitating embodied mental simulation through product orientation. Journal of Consumer Research, 38(6), 988-1003.

Eyal, T., Liberman, N. \& Trope, Y. (2008). Judging near and distant virtue and vice. Journal of Experimental Social Psychology, 44(4), 1204-1209.

Eyal, T., Liberman, N., Trope, Y. \& Walther, E. (2004). The pros and cons of temporally near and distant action. Journal of Personality and Social Psychology, 86(6), 781-795. 
Eyal, T., Sagristano, M. D., Trope, Y., Liberman, N. \& Chaiken, S. (2009). When values matter: Expressing values in behavioral intentions for the near vs. distant future. Journal of Experimental Social Psychology, 45(1), 35-43.

Falk, J. H. \& Balling, J. D. (2009). Evolutionary influence on human landscape preference. Environment and Behavior, 42(4), 497-493.

Förster, J., Friedman, R. S. \& Liberman, N. (2004). Temporal construal effects on abstract and concrete thinking: Consequences for insight and creative cognition. Journal of Personality and Social Psychology, 87(2), 177-189.

Fujita, K., Trope, Y., Liberman, N. \& Levin-Sagi, M. (2006). Construal levels and selfcontrol. Journal of Personality and Social Psychology, 90(3), 351-367.

Hagerhall, C. M., Purcell, T. \& Taylor, R. (2004). Fractal dimension of landscape silhouette outlines as a predictor of landscape preference. Journal of Environmental Psychology, 24(2), 247-255.

Hansen, J., \& Wänke, M. (2010). Truth from language and truth from fit: the impact of linguistic concreteness and level of construal on subjective truth. Personality and Social Psychology Bulletin, 36, 1576-1588.

Hartmann, P. \& Apaolaza, V. (2010). Beyond savanna: An evolutionary and environmental psychology approach to behavioral effects of nature scenery in green advertising. Journal of Environmental Psychology, 30(1), 119-128.

Hayes, A. F. (2013). Introduction to mediation, moderation, and conditional process analysis: A regression-based approach. New York: Guilford Press. 
Higgins, E. T. (2000). Making a good decision: Value from fit. American Psychologist, 55(11), 1217-1230.

Higgins, E. T. (2005). Value from regulatory fit. Current Directions in Psychological Science, 14(4), 209-213.

Higgins, E. T., Idson, L. C., Freitas, A. L., Spiegel, S. B. \& Molden, D. C. (2003). Transfer of value from fit. Journal of Personality and Social Psychology, 84(6), 1140-1153.

Kahle, L. B. \& Homer, P. M. (1985). Physical attractiveness of celebrity endorsers: A social adaptation perspective. Journal of Consumer Research, 11(4), 954-961.

Kamins, M. A. (1990). An investigation into the match-up hypothesis in celebrity advertising: When beauty may be only skin deep. Journal of Advertising, 19(1), 4-13.

Kaplan, S. (1987). Aesthetics, affect, and cognition: Environmental preference from an evolutionary perspective. Environment and Behavior, 19(1), 3-32.

Kent, S. (1995). Eyewitness art: Composition. London: DK ADULT

Khan, U., Zhu, M. \& Kalra, A. (2011). When trade-offs matter: The effect of choice construal on context effects. Journal of Marketing Research, 48(1), 62-71.

Ledgerwood, A., Wakslak, C. J. \& Wang, M. (2010). Differential information use for near and distant decisions. Journal of Experimental Social Psychology, 46(4), 638-642.

Lee, A. Y. \& Aaker, J. L. (2004). Bringing the frame into focus: The influence of regulatory fit on processing fluency and persuasion. Journal of Personality and Social Psychology, 86(2), 205-218. 
Lee, A. Y., Keller, P. A. \& Sternthal, B. (2010). Value from regulatory construal fit: The persuasive impact of fit between consumer goals and message concreteness. Journal of Consumer Research, 36(5), 735-747.

Liberman, N., \& Trope, Y. (1998). The role of feasibility and desirability considerations in near and distant future decisions: A test of temporal construal theory. Journal of personality and social psychology, 75(1), 5.

Liberman, N. \& Trope, Y. (2008). The psychology of transcending the here and now. Science, 322(5905), 1201-1205.

Liberman, N., Trope, Y. \& Wakslak, C. (2007). Construal level theory and consumer behavior. Journal of Consumer Psychology, 17(2), 113-117.

Livio, M. (2003). The golden ratio: The story of Phi, the world's most astonishing number. New York: Broadway Books.

Malaviya, P., Kisielius, J., \& Sternthal, B. (1996). The effect of type of elaboration on advertisement processing and judgment. Journal of marketing research, 33(4), 410421.

Marzocchi, G. L., Pizzi, G., \& Scarpi, D. (2016). When a picture's worth a thousand words: The effects of visual construal priming on information acquisition and choice. Marketing Letters, 27(3), 487-498.

McCrea, S. M., Liberman, N., Trope, Y., \& Sherman, S. J. (2008). Construal level and procrastination. Psychological Science, 19(12), 1308-1314.

McManus, I. C. \& Weatherby, P. (1997). The golden section and the aesthetics of form and composition: A cognitive model. Empirical Studies of the Arts, 15(2), 209-232. 
Meyers-Levy, J. \& Peracchio, L. (1992). Getting an angle in advertising: The effect of camera angle on product evaluations. Journal of Marketing Research, 29(4), 454-461.

Ostinelli, M., Luna, D. \& Ringberg, T. (2014). When up brings you down: The effects of imagined vertical movements on motivation, performance, and consumer behavior. Journal of Consumer Psychology, 24(2), 271-283.

Peracchio, L. A. \& Meyers-Levy, J. (2005). Using stylistic properties of ad pictures to communicate with consumers. Journal of Consumer Research, 32(1), 29-40.

Peterson, B. (2015). Learning to see creatively: Design, color, and composition in photography. New York: Amphoto Books.

Preacher, K. \& Hayes, A. (2004). SPSS and SAS procedures for estimating indirect effects in simple mediation models. Behavior Research Methods, Instruments and Computers, 36(4), 717-731.

Rosch, E. (1975). Cognitive representations of semantic categories. Journal of Experimental Psychology: General, 104(3), 192-233.

Slepian, M. L., Masicampo, E. J. \& Ambady, N. (2015). Cognition from on high and down low: Verticality and construal level. Journal of Personality and Social Psychology, $108(1), 1-17$.

Spassova, G. \& Lee, A. Y. (2013). Looking into the future: A match between self-view and temporal distance. Journal of Consumer Research, 40(1), 159-171.

Spencer, S. J., Zanna, M. P., \& Fong, G. T. (2005). Establishing a causal chain: why experiments are often more effective than mediational analyses in examining 
psychological processes. Journal of personality and social psychology, 89(6), 845851.

Svobodova, K., Sklenicka, P., Molnarova, K. \& Vojar, J. (2014). Does the composition of landscape pictures affect visual preferences? The rule of the golden section and the position of the horizon. Journal of Environmental Psychology, 38, 143-152.

Thompson, D. V., \& Hamilton, R. W. (2006). The effects of information processing mode on consumers' responses to comparative advertising. Journal of Consumer Research, $32(4), 530-540$.

Till, B. D. \& Busler, M. (2000). The match-up hypothesis: Physical attractiveness, expertise, and the role of fit on brand attitude, purchase intent and brand beliefs. Journal of Advertising, 29(3), 1-13.

Trope, Y. \& Liberman, N. (2000). Temporal construal and time-dependent changes in preference. Journal of Personality and Social Psychology, 79(6), 876-889.

Trope, Y. \& Liberman, N. (2003). Temporal construal. Psychological Review, 110(3), 403421.

Trope, Y. \& Liberman, N. (2010). Construal-level theory of psychological distance. Psychological Review, 117(2), 440-463.

Trope, Y. \& Liberman, N. (2011). Construal level theory. Handbook of Theories of Social psychology, Vol. 1 (pp. 118-134). Los Angeles: SAGE Publications.

Ulrich, R. S. (1983). Aesthetic and affective response to natural environment. In Behavior and the Natural Environment (pp. 85-125). New York: Springer US. 
Van Kerckhove, A., Geuens, M. \& Vermeir, I. (2015). The floor is nearer than the sky: How looking up or down affects construal level. Journal of Consumer Research, 41(6), $1358-1371$.

Van Rompay, T. J., de Vries, P. W., Bontekoe, F. \& Tanja-Dijkstra, K. (2012). Embodied product perception: Effects of verticality cues in advertising and packaging design on consumer impressions and price expectations. Psychology \& Marketing, 29(12), 919-928.

Wakslak, C. J., Trope, Y., Liberman, N. \& Alony, R. (2006). Seeing the forest when entry is unlikely: Probability and the mental representation of events. Journal of Experimental Psychology: General, 135(4), 641-653.

White, K., MacDonnell, R.\& Dahl, D. W. (2011). It's the mind-set that matters: The role of construal level and message framing in influencing consumer efficacy and conservation behaviors. Journal of Marketing Research, 48(3), 472-485.

Williams, L. E. \& Bargh, J. A. (2008). Keeping one's distance: The influence of spatial distance cues on affect and evaluation. Psychological Science, 19(3), 302-308.

World Health Organization. (2004). Guidelines for drinking-water quality: Recommendations, 1. Retrieved February 1, 2017, http://www.who.int/water_sanitation_health/dwq/GDWQ2004web.pdf.

Zatorre, R. J. \& Halpern, A. R. (2005). Mental concerts: Musical imagery and auditory cortex. Neuron, 47(1), 9-12.

Zhao, M., Hoeffler, S. \& Zauberman, G. (2007). Mental simulation and preference consistency over time: The role of process-versus outcome-focused thoughts. Journal of Marketing Research, 44(3), 379-388. 
Zhao, X., Lynch Jr, J. G., \& Chen, Q. (2010). Reconsidering Baron and Kenny: Myths and truths about mediation analysis. Journal of Consumer Research, 37(2), 197-206.

Zhao, M. \& Xie, J. (2011). Effects of social and temporal distance on consumers' responses to peer recommendations. Journal of Marketing Research, 48(3), 486-496.

\section{Further readings}

Human Solution, Ergonomic Office Desk, Ergonomic Chair, and Keyboard Height Calculator, https://www.thehumansolution.com/ergonomic-office-desk-chair-andkeyboard-height-calculator/" retrieved at August 28 2018. 